\title{
Trans-2-Enoyl-CoA Reductase, Mitochondrial
}

National Cancer Institute

\section{Source}

National Cancer Institute. Trans-2-Enoyl-CoA Reductase, Mitochondrial. NCI Thesaurus.

Code C89011.

Trans-2-enoyl-CoA reductase, mitochondrial (373 aa, $\sim 40 \mathrm{kDa}$ ) is encoded by the human MECR gene. This protein plays a role in the production of acyl-CoA. 